\title{
A Summary Study of Cultural Concepts
}

\author{
Qiaoling Chen ${ }^{1,}$,, Yue Dong ${ }^{2, b}$
}

\author{
${ }^{12}$ Shaanxi University of Science \& Technology, Xi'an, Shaanxi, 710021 \\ ${ }^{\mathrm{a}}$ email, ${ }^{\mathrm{b}}$ email
}

Keywords: Culture, Structure, Concept, Discussion

\begin{abstract}
In the ancient Chinese, "Culture" refers to the "cultural and educational", and the corresponding force of the conquest, the so-called "martial arts". Also refers to the use of "culture" to enlighten, infection, nurtured objects.
\end{abstract}

\section{Introduction}

Culture is the most understandable and difficult to explain concept in the social sciences. Easy to understand because each culture has its external form of expression, we live in a specific cultural context, and through some common channels often come into contact with other cultures, or directly with other cultural backgrounds of people, we It is very familiar with it. It is difficult to explain because the cultural implicit structure is very broad, vague and difficult to define. Standing on the basis of extensive research on the basis of this concept to be verified and analysis, is the urgent need for deep cultural research.

\section{The Origin of Cultural Concepts}

"Culture" in the ancient Chinese refers to the "cultural and educational", and the corresponding force of the conquest, the so-called "martial arts". Also refers to the use of "culture" to enlighten, infection, nurtured objects. "Book of Changes", "view of the humanities to become the world" can be seen as the ancient Chinese "culture" of the original formulation, Which "human culture into" is the real meaning of culture: culture, with humanities to become the world also; culture, humanization also. Kong Yingda in the "Zhou Yi justice" explained: "View of the humanities to become the world, the saints observes the humanities, then the book of music and music that, when the law of this teaching into the world also." This has been from the spirit of thinking Explain the cultural connotation and understand the meaning of culture from the conceptual level. Similar examples are some, such as the Western Han Dynasty Liu said: "Fan Wu of the Xing, for the ad also; culture does not change, and then add punish." Jin beam Zhe said: "cultural inscriptions, martial arts extravagant.", Each Liang Zhaoming Prince Xiao Tong said: "words to the cultural series and the inside, with Wu Dejia also far away also. "But these statements are very different from what we call" culture "today.

The concept of "culture" used in China is now thought to have been translated from Japanese at the end of the 19th century, and its origins in Latin culture. From the source point of view, the Latin culture has farming, living, practice, attention or attention, god, processing, cultivation, education, education, courtesy and other meanings. German, English, French "culture" word, all from the Latin culture. The original "American Encyclopedia" says: "Culture as a special term, appeared in the writings of anthropologists in the middle of the 19th century." $\mathrm{C}$ and the culture was specially studied in the second half of the 19th century, anthropology, sociology, Cultural and other disciplines after the rise, because these new disciplines are the main theme of the study of culture. Since then, many foreign scholars to the "culture" under the definition, but so far there is no unified view. American anthropologist Krupp and Clarkhon in the 1952 "culture, on the concept and definition of the review," a book listed as the 1951 definition of 164, that "culture" concept is difficult to grasp, reluctantly Made a definition of their own, that is, culture is a "derived from the abstract concept of behavior." 


\section{The Concept of Cultural Discussion}

The earliest definition of culture is given by the British human culture scientist Taylor. For the first time, he summed up and summed up the phenomenon of human culture from the height of cultural anthropology, and opened up a broader field of vision for cultural studies. Since then, Chinese and foreign scholars on the concept of culture and its connotation of a wide range of discussions, these discussions are mainly integrated:

British and American traditional cultural researchers most of the culture is understood as the sum of the various forms of established facts, that is, the sum of the material and spiritual achievements created by mankind. The famous American anthropologist Clarkhorn and Kelly argue that "culture is an entire cluster of things, and the whole cluster contains all the products of artifacts, beliefs, habits, and the activities of those who are determined by these habits." When we regard the general culture as a narrative concept, it is the treasure that is accumulated by human beings, that is, books, paintings, buildings, etc. In addition, we have the knowledge of personnel and the natural environment, that is, Language, customs, complete rituals, ethics, religion and morality are within the cultural sphere. " Many Chinese scholars agree with this view, such as the earlier study of Eastern and Western culture, Mr. Liang Shuming that:" culture, Is my life depends on everything ... ... often used to text, literature, thought, academic, education, publishing, etc. for the culture, but the narrow sense.I said that culture is my life depends on everything, intended to instruct people, Culture is a very real thing.Civilization of the original meaning, should be in the economy, politics, and even all-encompassing. " Taiwan scholar Qian Mu said:" Culture is the whole of human life, bringing together all the human life is' Culture '.' he in the "spirit of Chinese culture," a book and said: "Culture is a long period of large groups of collective public life. Such a view is often interpreted as a broad sense of culture in dictionaries, dictionaries, or encyclopedias in countries such as China and the former Soviet Union, such as the Encyclopedia of the Soviet Union (1973), which explains the general concept of culture as

And the people in the history of a certain level of development, it is manifested by people living and activities of the various types and forms, as well as people created by the material and spiritual wealth. "China in the" Xinhua Dictionary "gives a broad definition is: "Refers to the human in the process of social history created by the material wealth and spiritual wealth of the sum. "According to this broad definition, the whole world can be divided into two blocks: culture and nature, all created by the people are attributed to the cultural category; where no one is involved in nature.

German traditional cultural researchers tend to understand culture as a living or life-based living thing, that is, the pattern of life. They argue that cultural formality, institutionalization, and patterning mean cultural death. French scholar Victor El pointed out: "culture is the cultivation of intellectual, aesthetic and moral aspects of human beings." Culture does not include the sum of behavior, material creation and system. "Culture is the distribution of the remaining energy that mankind fully exploits." Bydyne argues that "the whole concept of culture encompasses the behavior, emotions and thoughts and knowledge of a person in society, Social and artistic ideal. The earliest definition of culture is the British human culture scientist Taylor, he published in 1865," the early history of human history and civilization development research "pointed out: culture is a complex overall, including knowledge, Art, religion, mythology, law, customs, and other social phenomena. In the book "Primitive Culture" published in 1871, he points out that "culture or civilization is a complex whole that includes knowledge, faith, art, morality, law, customs, and other people who are members of society All the ability and habits. In China, there are many scholars hold such views, such as Wei Qiuling that: "from the cultural and human survival relationship, the culture is the human adaptation of the environment and solve their survival problems, This way and means is through a certain social ideology formed by the values as the core of a series of behavioral norms and their corresponding systems and organizations to complete and achieve. "Gao Changmei, Wu Yuhong that:" social culture that culture is relative to the economic and political terms, it is always with a social economy, political companionship and promote each other. Culture is a very broad concept, in general, including the culture of knowledge, the culture of ideology and the culture of institutional form. In the Chinese dictionary, this view is generally interpreted as a narrow 
sense of culture, such as "Xinhua Dictionary" given on the broad definition of "emphasis on spiritual wealth, such as education, science, literature and so on." China's "Ci Hai The 1979 edition also explains the narrow culture as "the ideology of society, and the corresponding institutions and institutions". "Encyclopedia of the Soviet Union" (1973) the cultural concept of a broad and narrow sense of the distinction, as a narrow culture, "refers only to people's spiritual life."

It is argued that culture is a series of rules that guide a group of people to communicate, think, and between people or between people and the environment; others believe that culture is "a society in the formation of a group of shared observation and behavior standard". "The culture is the pattern of behavior of all groups," he said. "The culture is the pattern of behavior of all groups," says Benin and Du Ming. "Culture is the pattern of behavior of all groups. Life style, lifestyle is the observable nature of all the people. "Winston more clearly shows:" From an important sense, the culture is a social interaction of the product in a certain extent within the cultural behavior. The customary model of the individual is formed by the customary model of customization, within which human behavior is cultural behavior, and this established customary model is an integral part of culture, and the individual grows in culture. The sociologist Reed Bain says, "Culture is the sum of the behavior of the social symbols." scholars of this view will be a variety of human behavior and dominate the social behavior of the customs as a culture Fundamental contents.

Some scholars, especially historians of history, attach great importance to the historical inheritance of culture, and they tend to understand culture as a traditional form of social behavior or all social heritage. "The culture is the traditional form of behavior that is unique to society; sometimes it can be a group of people," he said, "that culture is the whole of the traditional act." The traditional form of behavior of the society; sometimes it can refer to the traditional form of behavior of a certain race; sometimes it can refer to the traditional form of behavior of a certain period; And the inheritance of the automatic response, habits, technology and value and the behavior derived from it is a cultural thing. ', Na Japanese cultural scientist grandfather Jiangxiao also believe that culture is "caused by the day after tomorrow to become Groups of members of the common and have been maintained between the behavior of the way. "The other two American scholars, Balg and Polgus, point out that" a culture of a group is the whole of its social heritage and its organization. " These inheritance have gained social significance, because each race has its own different temperament and the historical life of the group. "Misu Burland and Ude also pointed out that" culture contains everything that can be passed from this generation to another generation. A nation's culture is its social heritage. This social heritage contains knowledge, faith, art, morality, law, the use of tools, and the means of transport.

It is a general and general view that culture is primarily regarded as a summary of human art activities and ritual folk activities. As in the traditional concept of Western humanism, the territory of culture is the museum, library, theater, opera house, cinema and so on. Therefore, people usually talk about culture, often ruled out the economic, political and even education and other aspects of the concept of behavior. In fact, this understanding is still influential in the contemporary era, such as the establishment of the government departments in many countries with the industrial, scientific, educational and other departments of the Ministry of Culture. In China at all levels of local administrative institutions also set up a corresponding cultural bureau, cultural centers and the like, its business scope for the above areas. Some international institutions also understand this to construct the corresponding organization.

From the functional and value level to understand the meaning of culture is another concept of cultural ideas to explore. "A culture is a blueprint for life," says Moms, a group of influential people who, in spite of this blueprint, are particularly concerned with certain motivations of behavior and do not advocate other motives; or they prefer Some of the methods and do not use other methods to achieve these motives. "Consultation scholar Liang Qichao wrote in 1922 as" what is culture, "a paper that:" culture, human heart can be released from the valuable common industry 'Sun Yat - sen has also described the approximate view: "Simply put, culture is human

And they coincide with the British anthropologist Marinovsky as the representative of the functionalist cultural theory, this theory that culture is "a meet the requirements of the process, in 
order to cope with the The environment facing, the specific special issues, while the white has been placed in a better position on the device device. While the 20th century, the rise of the 1960s, "cultural interpretation of learning," the representative of Ge Erzu is the culture as a symbol and meaning of the system. He said: "Human beings are woven by the meaning of their own mesh support the animals... the so-called culture is such a mesh.

\section{References}

[1] "Shuoyuan • . Zhiwu."

[2] "Buwangshi • Youyi", transferred from the "Zhaoming anthology" Volume nineteen.

[3] "Zhaoming anthology" Volume nineteen.

[4] [France 1 Victor El: "cultural concept", Kang Xinwen, Xiaowen translation, Shanghai people People's Publishing House, 1988, pp. 5-54-55.

[5] Zhu Liuquan: "Introduction", "British culture and diplomacy", Qiqiu Feng, Feng Liang et al., P. Also ignore the heart Mu Township Zhang Zhongli, Zong Wenju: "Introduction to Chinese and Western culture", Tianjin University Press, 2004, 3-4, 6-7, 6, 9, 4, 5, 8 pages.

[6] Liang Shuming: "Chinese cultural essence", contained "Complete Works of Liang Shuming" Volume III, Shandong People's Publishing House, 1990, p. 9.

[7] Qian Mu: "culture and life", contained "the characteristics of Chinese culture", Taiwan World Bookstore (Taipei), 1969.

[8] Qian Mu: "Chinese cultural spirit", Taiwan three people bookstore [M], 1973, page 2. 1996, pp. 5-8. 